\title{
Retraction Note to: In vitro somatic embryogenesis from immature female flower of Musa AAB cv. Chenichampa and molecular analysis of transcript factors (TFs) during somatic embryogenesis
}

\author{
Nandhakumar Natarajan ${ }^{1}$. Sathish Sundararajan ${ }^{2}$. C. P. Suresh ${ }^{1} \cdot$ Sathishkumar Ramalingam ${ }^{1}$
}

Published online: 7 October 2020

(c) Springer Nature B.V. 2020

\section{Retraction to: Plant Cell, Tissue and Organ Culture (PCTOC) (2020) 142:339-351 \\ https://doi.org/10.1007/s11240-020-01866-7}

The authors have retracted the article [1] because subsequent experiments revealed that the majority of in vitro plants regenerated through somatic embryogenesis, especially after hardening, were found to contain somaclonal variations. The authors had confirmed the genetic stability in in vitro raised plants in a pool of regenerated plantlets as mentioned in the original article during the initial experiments in replicates. However, at a later stage during the acclimatization process a large pool of in vitro plants previously shown to have no genetic variations were found to lack genetic stability. Since this affects a key parameter of this study (i.e. the ability to produce true-to-type plants), the article may mislead the scientific community. The authors believe that the genetic stability of in vitro raised plants through the tissue culture process is very important and sincerely apologize for any inconvenience caused.

All authors agree with this retraction. The authors have been invited to submit a new manuscript for peer review.

\section{Reference}

1. Natarajan N, Sundararajan S, Suresh CP et al (2020) In vitro somatic embryogenesis from immature female flower of Musa $\mathrm{AAB} \mathrm{cv}$. Chenichampa and molecular analysis of transcript factors (TFs) during somatic embryogenesis. Plant Cell Tiss Organ Cult 142:339-351. https://doi.org/10.1007/s11240-020-01866-7

Publisher's Note Springer Nature remains neutral with regard to jurisdictional claims in published maps and institutional affiliations.

The original article can be found online at https://doi.org/10.1007/ s11240-020-01866-7.

Nandhakumar Natarajan

Nandhumn2020@gmail.com

1 Department of Horticulture, North Eastern Hill University, West Garo Hills, Meghalaya, India

2 Plant Genetic Engineering Laboratory, Department of Biotechnology, Bharathiar University, Coimbatore, India 